\title{
Is the Japanese Extended Family Altruistically Linked? A Test based on Engel Curves
}

\author{
Fumio Hayashi \\ Working Paper No. 80 \\ Fumio Hayashi \\ Department of Economics and East Asian Institute \\ Columbia University \\ December 1993
}

\begin{abstract}
Altruism has the well-known neutrality implication that consumption is invariant to division of resources within the family. We test this by estimating Engel curves for Japanese twogeneration households. The hypothesis that Engel curves are not affected by division of resources between parent and child can be strongly rejected. The food items whose budget share increases with parent's share of household income are precisely those favored by old generations such as cereal, fish, and vegetables.
\end{abstract}

Keywords: altruism, neutrality, Japanese extended family, co-residence JEL Classification: D11, D12, E21

The author is grateful to Robert Pollak and Mark Rosenzweig for enlightening discussions. The research reported here was supported by grants from National Science Foundation and National Institute of Aging. All the computations using Japanese data were done while my affiliation was with Osaka University.

Working Paper Series

Center on Japanese Economy and Business

Graduate School of Business

Columbia University

December 1993 


\section{Introduction}

In the standard model of the family, all members of the family jointly maximize a common objective function. This is because members are altruistic to each other, or because of the Rotten Kid Theorem of Becker (1981) that selfish members find it to their self interest to conform to the altruist's objective. The model has a strong neutrality implication that consumption is invariant to how resources are divided within the family as long as total family resources are controlled for. For the U.S., neutrality does not seem an adequate description of household behavior. Using data on individual households linked by parentchild relation, Altonji, Hayashi, and Kotlikoff (1992) have shown that the allocation of consumption across households forming a single family is closely related to division of income within the family. It would be interesting to see if neutrality fares better in other cultures that appear to value family ties. The purpose of this paper is to test neutrality for Japan.

Although there is no Japanese data on households linked by relation, a substantial fraction of a cross-section of Japanese households are extended families or two-generation households in which two adult generations co-reside. ${ }^{1}$ Since consumption data are for the household as a whole, it is not possible to study the allocation of total household consumption within two-generation households. Still, neutrality has an implication that, for each commodity, the household's total demand is invariant to division of resources between coresiding generations. We test this demand neutrality by checking whether a demand system,

1. According to the 1984 Basic Survey of Welfare Administration (Ministry of Health and Welfare, Government of Japan), p. 92, about $63 \%$ of all individuals 60 years or older in Japan live with their children. 
which in a cross-section of households is a collection of Engel curves, is affected by intergenerational division of resources. Demand would also be neutral if co-residing generations had identical tastes. However, it can be documented from data on Japanese nuclear households that food taste is very much generational.

If co-residence is a result of a residence status choice made by parent and child who could have lived separately as two separate nuclear households, the sample of two-generation households is a choice-based sample. Correcting the sample selection bias is very difficult, because nuclear households contained in our data set are not linked by relation, providing no information on the characteristics of parent-child pairs that chose living apart over coresidence. Consequently, we ignore the sample selection bias in our estimation of Engel curves. This is probably innocuous, because the Engel curves we estimate are for a subset of commodities (food). We will provide in section 4 an example in which the endogeneity of the residence status does not bias parameter estimates of Engel curves.

The idea of testing whether demand is neutral is not new. There is a literature on the invariance of demand to division of resources between spouses. ${ }^{2}$ However, a typical testing procedure is to see if non-earned income of husband and wife has the identical effect on demand, with no attempt to control for total resources. If, for example, husband's income is more permanent than wife's, then under neutrality husband's income should have more weight for demand because it is more closely related to total resources. Our Engel curve-based test does not have this problem because total consumption expenditure in Engel curves serves as a perfect control for the household's total resources. Also, to our knowl-

2. See, e.g., Cai (1989), Schultz (1990), and Thomas (1990). 
edge this paper is a first attempt to test neutrality of household demand to intergenerational distribution, which, from the viewpoint of macroeconomics, would be more interesting than testing neutrality within generations.

The content of the paper is as follows. In the next section, section 2, we briefly describe the Japanese cross-section data set of about fifty thousand households, more than one-fifth of which are two-generation households. Section 3 documents some stylized facts about determinants of co-residence and the generational difference in food tastes. In section 4 we examine altruistic models of the residence status and make precise the sense neutrality entails on two-generation households in these models. We also provide a parametric example which is capable of explaining the stylized facts about co-residence and in which the sample selection bias for Engel curves does not exist. Section 5 present our Engel curvebased test of demand neutrality. Section 6 contains a few concluding remarks.

\section{The Data}

The data we utilize is the 1984 wave of the National Survey of Family Income and Expenditure (NSFIE) conducted by the Japanese government every five years since 1959. We briefly describe the aspects of the data relevant to the present study; a detailed description and evaluation of the data can be found in Hayashi, Ando and Ferris (1988). The survey consists of two cross-section data sets: about four thousand singles and about fifty thousand non-singles households. The sampling ratio differs between singles and non-singles as well as between geographical regions. On average, singles are under-represented by a factor of three. Respondents are required to keep a diary on hundreds of expenditure and receipt items throughout the three-month period of the survey from September to November (for 
singles in 1984, the survey is for September only). In the last month of the survey, the respondent reports information on the household's financial assets, consumer durables, and annual income for the latest 12 -month period. Each income component (e.g., employment income, interest and dividend income) is broken down by household member, but the breakdown is rather coarse: "head", "spouse", and "all other household members", where "head" is defined to be the main income earner.

A very important fact about Japanese households, which is well reflected in the data, is the prevalence of two-generation households (extended families). For reasons to be made clear in the next paragraph, we take a rather narrow definition of a two-generation household. Define an adult to be an individual who is either working, 25 years or older, married, or the head of a singles household, and a generation to be either a married couple or an unmarried adult. If the generation is a couple, its age is the average age of the couple. We define a two-generation bousebold to be a household of two generations sharing the same budget, one of which is the father, mother, or both, of the other generation, such that: (1) the older generation be 55 or older while the younger generation be less than 55 years of age, (2) there be no other adults, and (3) the older generation have no non-adult co-residing children. Accordingly, a nuclear bousebold is a generation with or without non-adult coresiding children. Thus singles are a nuclear household. A nuclear household is either a young nuclear bousebold whose generation is younger than 55 , or an old nuclear bousebold 55 or older. We require, in line with the definition of two-generation households, that old nuclear households have no non-adult co-residing children.

We adopt the age requirement (requirement (1) above) so that we can compare generations living with their offspring with those living alone; any generation 55 or older 
is either in the pool of old nuclear households or the older generation of a two-generation household. Similarly, any generation younger than 55 is either in the pool of young nuclear households or the younger generation of a two-generation household. We will exploit this facet of the data to study the choice of residence status (live alone or co-reside) for the old and the young. Requirement (2) is dictated by the coarse breakdown of household income by member mentioned above. We will equate the income of the non-head generation with that of "all other household members". If there were other adults in the two-generation household, the non-head generation's income thus identified would include their income as well. Requirement (3) is adopted for convenience and simplicity. There are very few old generations that have non-adult co-residing children in the data. For the same reason we ignore three-adult generation households.

Figure 1 should make it clear how we create three samples - two-generation households, young nuclear households, and old nuclears - from two raw data sets (one on singles and the other on non-singles). Elimination of cases with officially designated missing values for relevant variables reduces the data set size to 3,924 for singles and 47,393 for nonsingles. These $51,317(=3,924+47,393)$ records are directed to 32,266 nuclear, 12,265 twogeneration, and 6,786 other households. After the application of the age requirement and the requirement that the older generation have no non-adult children, there are 26,498 young nuclear, 5,538 old nuclear, and 10,068 two-generation households. Using the survey's definition of the head (the main income earner), we can further divide the sample of twogeneration households into two parts: those whose head is the older generation (3,386 households) and those whose head is the younger generation (remaining 6,682 households). 


\section{Stylized Facts}

Sample means of selected variables for the three samples are displayed in Table 1. For two-generation households, household income can be divided between the two generations, while expenditures are for the household as a whole. Income and expenditures are as in the raw data, with no modifications and imputations to make them conformable to national income accounts definitions. ${ }^{3}$ The sample means in the table are weighted by the sampling weights provided by the survey (see notes to Table 1 for more details).

The following are the noteworthy points about the table.

(1) Comparison of the sample size and the estimated population size for old nuclear and two-generation households confirms that the majority of old individuals live with their children.

(2) The old generation's marital status does not depend heavily on the residence status, although widows are somewhat more likely to be in two-generation households.

(3) On the other hand, the old generation's income depend on the residence status: it is less for those co-residing with offspring. This is partly due to the high fraction of the old in two-generation households reporting zero income (see line 10). As discussed in Appendix, there is reason to believe that some of them are false zeros, i.e., missing cases with positive income mis-coded as zeros. However, also as discussed in Appendix, the extent of possible mis-coding is probably not enough to alter the conclusion. The same is true for the young, albeit to a much less degree.

3. A detailed discussion of how the raw data should be adjusted to national income accounts definitions and for under-reporting can be found in Hayashi et. al. (1989). 
(4) The incidence of annual private monetary transfer receipts (see line 12) for two-generation households are low because transfers between parents and children are internal and hence not recorded. For young nuclear households, the annual transfer incidence of $5 \%$ (see line 13) is much less than the annual incidence reported for the U.S. of about $20 \%{ }^{4}$ On the other hand, the average transfer amount among those who received transfers is a much larger fraction of their income for Japan than for the U.S.

(5) There is a substantial difference in the pattern of food expenditure between young and old nuclear households. ${ }^{5}$ The young prefer "western" staples such as meat and dairy products while the old spend a higher fraction of food budget on cereal, fish, and vegetables. Somewhere in the middle lies the food expenditure pattern of two-generation households. Whether this food pattern is influenced by division of resources within two-generation households is the main question to be addressed in the paper.

Another noteworthy fact about two-generation households is that the older generation's income is negatively correlated with the younger generation's, as shown in Figure 2. The correlation for pairs reporting positive values is -0.12 . If false zeros were identified and taken into the calculation, the negative correlation would have been stronger.

To explore factors determining the residence status, we estimated a Probit coresidence equation. Since we have no information for nuclear families on variables pertain-

4. See Rosenzweig and Wolpin $(1992,1993)$ (which uses the NLS (National Longitudinal Survey)), and Altonji, Hayashi and Kotlikoff (1993) and Ioannides and Kan (1993) (which use the Panel Study of Income Dynamics).

5. Of course this could be due to differences in demographics and income. We will show that the strong age effect remains even after controlling for those factors by estimating Engel curves on the sample of nuclear families in section 5 . 
ing to the parents or adult children of the head, we have to deviate from the more desirable specification of including both parents' and offspring's labor incomes. We instead estimate the co-residence equation separately for the young and the old. The dependent variable takes a value of $O$ (living apart) if the observation is from nuclear households and 1 (coresidence) if from two-generation households. Thus the sample size is $36,566(=26,498+$ $10,068)$ for the young and $15,606(=5,538+10,068)$ for the old. To control for the possible mis-coding that produced many zero incomes, we include a zero income dummy for the relevant income component as an independent variable.

Column 1 of Table 2 reports the co-residence equation for the young. The base for the marital dummy variables is couples, so that, for example, the positive coefficient on the dummy for single males imply that single males are more likely to co-reside with parents than couples. The number of non-adult children of the younger generation and the working wife dummy have positive coefficients, most likely due to the child care services provided by co-residing parents. Even after the effect of zero income is controlled for, income has a negative effect on co-residence. ${ }^{6}$ The corresponding co-residence equation for the old is in column 2 of the table. The negative effect of income on co-residence is highly significant for the old, particularly for pension income, which is consistent with the view that the development of social security has contributed to the decline of extended families. ${ }^{7}$ The negative coefficient on capital income reported in column 3 of the table means that those

6. This is consistent with the studies by Kotlikoff and Morris (1990) and by Rosenzweig and Wolpin (1993) for the U.S. Because they were able to match parents with children in their data sets, their coresidence equation has both the parent's and child's income. Both incomes have negative coefficients. 7. See, e.g., Soldo and Lauriat (1976). 
with high bequeathable wealth tend to live apart from children. ${ }^{8}$

We also estimated a monetary transfer receipts equation by Tobit. Unlike the coresidence equation, the sample excludes two-generation households because most monetary transfers are internal for two-generation households. As in the co-residence equation, variables pertaining to the other generation are not included. Capital income is excluded to avoid endogeneity bias. The Tobit estimates reported in Table 3 show that labor income has a negative and highly significant effect on transfer receipts. Its magnitude is much larger for the young, perhaps because transfer from parents is timed to alleviate liquidity constraints. ${ }^{9}$ The coefficient on the number of non-adult children implies that an additional child increases transfer receipts by 300 thousand yen per year. ${ }^{10}$

\section{Altruistic Models of Co-residence}

In this section we will examine models of co-residence in which an altruistic family, consisting of a parent generation $(\mathrm{P})$ and its offspring $(\mathrm{K})$, chooses between living apart to form two separate nuclear households and co-residence in a two-generation household, and show that demand neutrality - invariance of consumption demand to division of resources within families - holds for families choosing co-residence. We will also argue that neutrali-

8. These results are in sharp contrast to those in Ohtake (1992), which reports for a different sample of Japanese households that bequeathable wealth has a positive effect on co-residence while the effect of pension income is insignificant. Due to data limitations, the form of co-residence he considered is the so-called quasi-residence which is that the two generations live under the same roof but do not share a common budget. Our result about the effect of bequeathable wealth is consistent with Ando and Kennickell (1987) using the 1974 and 1979 wave of the NSFIE.

9. Cox and Jappelli (1990) shows for the U.S. that private transfers are targeted to those that are liquidity constrained.

10. This is consistent with the results from the NLS that the number of children increases the incidence of transfer receipts. See Rosenzweig and Wolpin (1992). 
ty is unlikely to hold if the two generations are not altruistic.

\subsection{Housing as a Public Good}

The family wishes to maximize

$$
\theta \mathrm{u}_{\mathrm{P}}\left(\mathrm{c}_{\mathrm{P}}, \mathrm{h}_{\mathrm{P}}, \varepsilon_{\mathrm{P}} ; \mathrm{r}\right)+(1-\theta) \mathrm{u}_{\mathrm{K}}\left(c_{\mathrm{K}}, \mathrm{h}_{\mathrm{K}}, \varepsilon_{\mathrm{K}} ; \mathrm{r}\right), 0<\theta<1
$$

where $u_{i}$ is generation i's own utility function $(i=P, K), h_{i}$ is housing services, $\varepsilon_{i}$ an unobservable taste shifter, $c_{i}$ a non-housing consumption vector, and $r$ is the residence status (live apart or co-reside) which affects the utility functions. When the two generations live apart, the budget constraints for two separate nuclear households are combined through monetary transfers into a single constraint

$$
p^{\prime}\left(c_{P}+c_{K}\right)+q\left(h_{P}+h_{K}\right)=y_{P}+y_{K},
$$

where $y_{i}$ is generation i's income, $p$ is the non-housing consumption price vector, and $\mathrm{q}$ is the price of housing services. When they live together to form a single two-generation household, housing is a public good. The budget constraint is

$$
p^{\prime}\left(c_{P}+c_{K}\right)+q h=y_{P}+y_{K},
$$

where $\mathrm{h}$ is the common housing consumption. The family chooses the residence status that yields higher family utility.

For later use, we note that the family's problem in the case of co-residence can be expressed as follows. The family's induced preferences over total consumption are give by:

$$
\mathrm{u}\left(\mathrm{c}, \mathrm{h}, \theta, \varepsilon_{\mathrm{P}}, \varepsilon_{\mathrm{K}} ; \mathrm{r}\right)=\max (4.1) \text { subject to: } \mathrm{c}_{\mathrm{P}}+\mathrm{c}_{\mathrm{K}}=\mathrm{c} \text { and } \mathrm{h}_{\mathrm{P}}=\mathrm{h}_{\mathrm{K}}=\mathrm{h} .
$$

So the family's problem is to maximize the induced family utility subject to the budget constraint $p^{\prime} c+q h=y_{P}+y_{h}$. This way of looking at the problem is useful because we 
do not observe individual consumption vector $\left(c_{\mathrm{P}}, c_{\mathrm{K}}\right)$ - all we observe is total consumption c - for two-generation households.

The model has a neutrality property: given total family resources (in this static model represented by $\mathrm{y} \equiv \mathrm{y}_{\mathrm{P}}+\mathrm{y}_{\mathrm{K}}$ ), consumption demand does not depend on how total family resources are divided within the family. To be more precise, neutrality for two-generation households has two parts. The first is demand neutrality. As clear from the discussion of the induced utility (4.4), the arguments of household demand function include prices, total consumption expenditure (which in this static model coincides with $\mathrm{y}$ by the budget constraint), and taste shifters, but not division of total resources. The second is the neutrality of residence status choice: the choice is a function of taste shifters and total resources $\left(\theta, \varepsilon_{\mathrm{P}}, \varepsilon_{\mathrm{K}}, \mathrm{y}\right)$ but not of division of total resources. Since the residence status choice is endogenous, there is a sample selection bias in that the distribution of taste shifters entering the demand function for two-generation households is already conditional on coresidence. An implication of the neutrality of residence status choice is that the conditional distribution does not depend on individual resources as long as it is conditional on total resources.

\subsection{An Example}

To illustrate these points, consider the following log-linear example, which also can explain the stylized facts about the relationship between co-residence and income documented in the previous section. The utility function is

$$
u_{i}\left(c_{i}, h_{i}, \varepsilon_{i} ; r\right)=v_{i}\left(c_{i}\right)+\lambda(r) \log \left(h_{i}\right), \quad i=P, K,
$$

where $\lambda$ (live apart) $=1$ while $\lambda$ (co-residence) $\equiv \lambda<1$, to reflect the disutility of co- 
residence arising from the loss of privacy. Let $\mathrm{v}_{\mathrm{i}}($.$) be such that its indirect utility function$ takes the following Gorman polar form: ${ }^{11}$

$$
\left[\log \left(\mathrm{x}_{\mathrm{i}}\right)-\log \left(\mathrm{a}\left(\mathrm{p}, \eta_{\mathrm{i}}\right)\right)\right] / \mathrm{b}(\mathrm{p}), \quad \mathrm{i}=\mathrm{P}, \mathrm{K},
$$

where $x_{i}$ is nominal expenditure on non-housing consumption; this $x_{i}$ should replace the $\mathrm{p}^{\prime} \mathrm{c}_{\mathrm{i}}$ in the budget constraints (4.2) and (4.3). The taste shifter, $\varepsilon_{\mathrm{i}}$, has two elements $\left(\eta_{\mathrm{i}}\right.$, $\lambda$ ). It is easy to show that the family chooses co-residence if and only if $y \leq y^{*}$, where the threshold income level $y^{*}$ is given by ${ }^{12}$

$$
\log \left(\mathrm{y}^{*}\right)=\phi(\theta, \lambda)+\log (\mathrm{q})
$$

Note that the taste shock $\eta_{\mathrm{i}}$ does not affect the residence status because its effect on family utility does not depend on the residence status.

The induced family utility (4.4) in terms of non-housing expenditure and housing consumption for two-generation households becomes

$$
\left[\log (\mathrm{x})-\log \left(\mathrm{a}\left(\mathrm{p}, \eta_{\mathrm{P}}, \eta_{\mathrm{K}}\right)\right)\right] / \mathrm{b}(\mathrm{p})+\lambda \log (\mathrm{h})
$$

where $\mathrm{x}=\mathrm{x}_{\mathrm{P}}+\mathrm{x}_{\mathrm{K}}$ is total non-housing expenditure and $\log \left(\mathrm{a}\left(\mathrm{p}, \eta_{\mathrm{p}}, \eta_{\mathrm{K}}\right)\right)=\theta \log \left(\mathrm{a}\left(\mathrm{p}, \eta_{\mathrm{P}}\right)\right)$ $+(1-\theta) \log \left(a_{K}\left(p, \eta_{K}\right)\right)$. Thus the strong separability between housing and non-housing consumptions that we assumed for individual utility functions is preserved.

The share of housing expenditure, $q h /(x+q h)$, equals $\lambda b(p)$, which does not involve division of resources, verifying demand neutrality. The taste shifter entering the share

11. Particular parameterizations of this Gorman polar form include the Translog model of Christensen, Jorgenson, and Lau (1975) and the Almost Identical Demand System of Deaton and Muelbauer (1980). The $b(p)$ in (4.6) can depend on the generation but it complicates the calculation without affecting the points to be made.

12. The $\phi$ function in (4.7) is: $-[\theta \log (\theta)+(1-\theta) \log (1-\theta)] /(1-\lambda)-\log (b)+\lambda \log (\lambda) / \lambda-[(1+b \lambda) \log (1+b \lambda)$ $-(1+b) \log (1+b)] /(\beta(1-\lambda))$. 
equation is $\lambda$. Its mean conditional on co-residence, $y$, and any indicator, say $d$, of division of $y$ does not depend on $d$ because $E(\lambda \mid$ co-residence, $y, d)=E\left(\lambda \mid y \leq y^{*}, y\right.$, $d)=E[\lambda \mid \log (y) \leq \phi(\theta, \lambda)+\log (q), y, d]=E[\lambda \mid \log (y) \leq \phi(\theta, \lambda)+\log (q), y]$.

Clearly, this example can explain why income is lower for generations who co-reside (see stylized fact (3) in the previous section), and why either generation's income has the negative effect in the Probit co-residence equation of Table 2: unless $y_{P}$ and $y_{K}$ are strongly negatively correlated, $\operatorname{Pr}\left(y \leq \mathrm{y}^{*} \mid \mathrm{y}_{\mathrm{i}}\right)$ decreases with $\mathrm{y}_{\mathrm{i}}$. It also explains the negative correlation shown in Figure 2, because the correlation between $y_{P}$ and $y_{K}$ conditional on co-residence (i.e., conditional on $y_{P}+y_{K} \leq y^{*}$ ) can be negative even if the unconditional correlation is positive. Finally, that the threshold income $\mathrm{y}^{*}$ increases with housing costs (q) is consistent with the prevalence of co-residence in a high housing price country like Japan.

\subsection{Time Transfers}

We have supposed that the benefit from co-residence is returns to scale in housing. Is neutrality specific to how we model the costs and benefits of co-residence? Another plausible reason for co-residence is the ease of time transfers. To focus on time transfers, consider the following altruistic model:

$$
\begin{aligned}
& \max \theta \mathrm{u}_{\mathrm{P}}\left(\mathrm{c}_{\mathrm{P}}, \mathrm{t}_{\mathrm{K}}, \ell_{\mathrm{P}} ; \mathrm{r}\right)+(1-\theta) \mathrm{u}_{\mathrm{K}}\left(\mathrm{c}_{\mathrm{K}}, \mathrm{t}_{\mathrm{P}}, \ell_{\mathrm{K}} ; \mathrm{r}\right) \\
& \text { subject to: } \mathrm{p}^{\prime}\left(\mathrm{c}_{\mathrm{P}}+\mathrm{c}_{\mathrm{K}}\right)=\mathrm{w}_{\mathrm{P}}\left[\mathrm{T}-\delta(\mathrm{r}) \mathrm{t}_{\mathrm{P}}-\ell_{\mathrm{P}}\right]+\mathrm{w}_{\mathrm{K}}\left[\mathrm{T}-\delta(\mathrm{r}) \mathrm{t}_{\mathrm{K}}-\ell_{\mathrm{K}}\right]
\end{aligned}
$$

where $T$ is time endowment, $t_{i}(i=P, K)$ is time spent by generation $i$ with the other generation, $\ell_{\mathrm{i}}$ is leisure, $\mathrm{w}_{\mathrm{i}}$ is the wage rate, and $\delta(\mathrm{r})$ is an (inverse) efficiency index of time transfer which equals 1 if $r=$ co-residence and $\delta(>1)$ if $r=$ live apart. 
The induced family utility given the residence status $r$ is given by

$$
\begin{aligned}
& \mathrm{u}\left(\mathrm{c}, \mathrm{n}_{\mathrm{P}}, \mathrm{n}_{\mathrm{K}}, \varepsilon_{\mathrm{P}}, \varepsilon_{\mathrm{K}} ; \mathrm{r}\right)=\max (4.9) \\
& \text { subject to: } \mathrm{c}_{\mathrm{P}}+\mathrm{c}_{\mathrm{K}}=\mathrm{c}, \delta(\mathrm{r}) \mathrm{t}_{\mathrm{P}}+\ell_{\mathrm{P}}=\mathrm{T}-\mathrm{n}_{\mathrm{P}}, \delta(\mathrm{r}) \mathrm{t}_{\mathrm{K}}+\ell_{\mathrm{K}}=\mathrm{T}-\mathrm{n}_{\mathrm{K}},
\end{aligned}
$$

where $n_{i}(i=P, K)$ is labor supply or hours worked. The family's problem conditional on co-residence is to maximize (4.10) subject to $\mathrm{p}^{\prime} \mathrm{c}=\mathrm{w}_{\mathrm{P}} \mathrm{n}_{\mathrm{P}}+\mathrm{w}_{\mathrm{K}} \mathrm{n}_{\mathrm{K}}$, which makes it clear that demand neutrality is conditional on hours worked: household demand $c$ is invariant to individual wages, given prices, taste shifters, total consumption expenditure $\mathrm{p}^{\prime} \mathrm{c}$, and hours worked. ${ }^{13}$ However, the residence status choice now depends on individual wages, thanks to the price effects of wages on hours worked.

\subsection{Non-altruistic Models of Co-residence}

Is neutrality a hallmark of altruism? To be sure, altruism is not a prerequisite for co-residence; models of co-residence for two selfish agents wishing to share benefits from coresidence can readily be found from the literature on marriage. In the Nash cooperative bargaining models of marriage, ${ }^{14}$ the equilibrium is assumed to be Pareto efficient. So consumption maximizes the weighted utility (4.1) for some $\theta$. The difference from the altruistic model is that the weight $\theta$ depends on division of total resources because so does the threat point. Therefore, neutrality would not hold for non-altruistic models of coresidence that assume Pareto efficiency.

One can view the model of non-cooperative provision of a public good as a non-

13. If consumption $c$ is weakly separable from hours worked in the induced utility function, or if hours worked are the same across households, as in the model of section 4.1, then demand neutrality is unconditional on hours worked.

14. See the literature cited in Behrman (1992). 
cooperative model of co-residence with housing being the public good. Warr (1983) and Bergstrom, Blume, and Varian (1986) have shown that consumption is invariant to division of resources if both agents make strictly positive donations to the public good. However, their result should be interpreted with care. First, the pairs of agents who play the public goods game may be self-selected and the selection may depend on individual incomes. Second, as Lundberg and Pollak (1993a) note, corner solutions are plausible in the case of multiple public goods. Third, one can question whether the one-shot non-cooperative approach is appropriate for modeling the parent-child relationship. ${ }^{15}$

\section{Testing Neutrality}

\subsection{Specification of Engel Curves}

As seen in the previous section, neutrality implies that the system of demand functions for two-generation households do not involve any indicator of how total resources are divided between two generations. In cross-section data with common prices to all households, demand functions are Engel curves. We test neutrality by including intrahousehold division indicators in Engel curves and checking for their significance in these augmented Engel curves. In order to implement the test, we have to address four issues.

The first issue is treatment of durables. The total consumption expenditure in Engel curves includes service flows from durables. But there is evidence from a separate Japanese micro data that all commodities except food are (psychologically) durable. ${ }^{16}$ For such

15. Lundberg and Pollak (1993b) show that neutrality does not hold in a repeated game context. 16. See Hayashi (1985). His estimate of the depreciation rate for recreational expenditure is $5 \%$ per year. 
commodities it is impossible to calculate service flows because there is no information on cumulative expenditures. We avoid this difficulty by assuming that food is weakly separable from other commodities in the induced family utility and focus on the allocation of food expenditure among food components. Weak separability will be tested below.

The second issue is treatment of hours worked. Lacking information on hours worked and wage rates, we are too constrained to provide a completely satisfactory treatment here. Available evidence (see Browning and Meghir (1991) for the U.K.) is that hours worked and food are not weakly separable, and indeed in our data when employment status is included in Engel curves it is statistically significant. Thus food demand must be conditioned on hours worked, as in section 4.3, but we do not have valid instruments such as wage rates for hours worked in our data. Thus, we are forced to make an untestable assumption that hours worked are exogenous. Furthermore, hours worked will be proxied by two dummy variables for work and part-time work.

Third, food expenditure, being a function of taste shifters, is an endogenous variable which we instrument by the household's (current) income, its square, capital income, its square, and net financial assets. Under the assumption that hours worked are exogenous, both capital income and labor income (which is part of current income) are valid instruments.

Fourth and most important, we have to deal with the possible sample selection bias. Since the distribution of unobservable taste shifters entering Engel curves as the errer term for two-generation households is already conditional on co-residence, the error term may be correlated with instruments (e.g., income) that affect the residence status choice. Correcting the bias is very difficult. The standard Heckit procedure is infeasible here 
because our sample of nuclear households are not linked by relation, providing no information on the characteristics of families having chosen living apart. ${ }^{17}$ Thus we are forced to ignore the sample selection bias. This is less onerous than it sounds, since the Engel curves we estimate are only a sub-system of demand functions. In fact, in the example given in section 4.2, the taste shifters entering non-housing demand, $\eta_{\mathrm{P}}$ and $\eta_{\mathrm{K}}$, do not enter the residence status choice, so there exists no sample selection bias, provided that $\eta_{\mathrm{P}}$ and $\eta_{\mathrm{K}}$ are independent of the taste shifters that do enter the residence status choice. Also, if the error term in Engel curves are dominated by measurement error, no bias arises.

\subsection{Engel Curves for Nuclear Housebolds}

Before proceeding to test the hypothesis, we document that there is a substantial intergenerational difference in tastes for food by estimating Engel curves for nuclear households, which may also be of independent interest. The form of Engel curves we entertain permits some functional flexibility:

$$
s_{j}=z^{\prime} \alpha_{j}+\beta_{j} x^{\{\gamma\}}+\eta_{j}, \text { with } x^{\{\gamma\}} \equiv\left(x^{\gamma}-1\right) / \gamma,
$$

where $x^{\{\gamma\}}$ is the Box-Cox transform, $x$ is nominal food expenditure for the household in question, $z$ is a vector of demographics (including age) and employment status for the household, $s_{j}$ is the share (in percents) of the $\mathrm{j}$-th food component in food budget, and $\eta_{j}$ is the error term. Following Blundell, Browning, and Meghir (1989), we try three values for $\gamma: \gamma=1,0,-1$. If $\mathrm{p}$ is the price vector, the Engel curves (5.1) can be derived from the indirect utility function $[\mathrm{x} / \mathrm{a}(\mathrm{p})]^{\}-\gamma\}} / \mathrm{b}(\mathrm{p})$, which reduces to the indirect (sub)utility function

17. For example, if the explanatory variable in the Probit selection equation is income, we need for limit observations (families whose residence status choice is live apart) the sum of parent's income and child's income. 
in section 4.2 when $\gamma=0$, quasi-homothetic preferences when $\gamma=-1$, and quadratic Engel curves when $\gamma=1 .{ }^{18}$ As in Table 1, we divide food into six food components: cereal, fish, meat \& dairies, vegetables, eating out, and other food.

We assume that the error term is conditionally homoskedastic because parameter estimates under the more general case of conditional heteroskedasticity are very similar. Then, since both the instruments and the right-hand-side variables are the same across equations, the three-stage least squares reduces to the two-stage least squares. Table 4 reports the two-stage least squares estimation of the five equation system for the sample of 32,036 nuclear households (26,498 young nuclear plus 5,538 old nuclear households). The Engel curve for the sixth food component, other food, is dropped because it is a linear combination of the first five Engel curves.

Panel A of the table shows parameter estimates for the log case $(\gamma=0)$; those for $\gamma=1$ or -1 are similar and not reported here. The results accord very well with our a priori expectations. Cereal is more important for households with children perhaps because of their higher calory needs. The share of eating out depends heavily on wife's employment status and increases with food expenditure. The substantial reduction in the residual variation for eating out is mostly due to the sample's inclusion of singles which tend to eat out much more frequently. More importantly, the household's age very strongly affects budget shares. The old spend more on cereal, fish, and vegetables, and less on eating out. We computed several diagnostics statistics, some of which are reported in Panel B. ${ }^{19}$

18. For $\gamma=-1$, the shape of (5.1) depends on how $\mathrm{x}$ is scaled. We deflate food expenditure $\mathrm{x}$ by its sample mean.

19. The Hausman exogeneity test is not reported here because the test statistic was extremely large or (less frequently) negative. In particular, the OLS estimate of the coefficient of $x^{\{\gamma\}}$ is very different 
The Sargan statistic for the five equation system is highly significant. ${ }^{20}$ This may not be totally surprising given the very large sample size. To test weak separability, we added the same Box-Cox transform of medical expenditure to the share equations, treating it as endogenous. ${ }^{21}$ The Wald statistic for joint significance in the five equations is fairly large, but not overwhelmingly so.

In sum, despite some evidence of mis-specification, our estimation of Engel curves for nuclear households has served our purpose: it unambiguously confirms the very strong effect of age on the structure of food demand.

\subsection{Engel Curves for Two-Generation Housebolds}

We now turn to the sample of two-generation households to test neutrality. We use the same form of Engel curves (5.1), with the $z$ vector now including demographics and employment statuses of two generations. We use two indicators of intra-household division of resources: parent's share of household income, $y_{P} /\left(y_{P}+y_{K}\right.$ ) (where $y_{P}$ and $y_{K}$ are parent's and child's current incomes) and the dummy that parents are the head of household. ${ }^{22}$ Under the maintained hypothesis that labor supply is exogenous, parent's income share can be treated as exogenous. The household head dummy is also exogenous because

from the two-stage least squares estimate; the $\log$ food coefficient in the share equation for cereal, for example, is -3.2 .

20. The Sargan statistic for the system is calculated as: $e^{\prime}\left(S^{-1} \otimes X\left(X^{\prime} X\right)^{-1} X\right)$ e where $e^{\prime}=\left(e_{1}{ }^{\prime}, \ldots, e_{5}{ }^{\prime}\right)$, $e_{j}$ is the residual vector from the $j$-th equation, $X$ is the matrix of instruments, and $S$ is the $5 \times 5$ residual covariance matrix. The degrees of freedom are 20 because the number of instruments exceeds that of the right-hand-side variables by 4 in each equation.

21. We also tried total nondurables expenditure (total expenditure less durables) instead of medical expenditure to test weak separability, but because of a serious multicollinearity between food and nondurables the parameter estimates were imprecise and the test was inconclusive.

22. Parent's share of household capital income is also tried, but because of numerous cases with zeros, it was not significant. Hayashi et. al. (1988) argues that capital income in the NSFIE is severely underreported. 
the head is defined as the main income earner. Thus the complete set of instruments is: demographics and employment statuses for two generations, household income, its square, household capital income, its square, net financial assets, and the two resource division indicators.

Table 5 presents results from our estimation of augmented Engel curves. Again, the parameter estimates are not very sensitive to the value of $\gamma$ in the Box-Cox transform, so in Panel A we present relevant coefficients for the log case (where $\gamma=0$ ). In four of the five equations, either indicator comes out strongly. The Wald statistic for the hypothesis that the coefficients of the two indicators are zero in all five equations, also reported in Panel A of the table, implies that demand neutrality can be rejected rather decisively. Furthermore, the coefficients's sign pattern accords with the age effect shown in Table 4 for nuclear households: the expenditure share rises with parent's share of household resources precisely for food components favored by the old.

The Sargan statistic, reported in Panel B of the table, is fairly significant, possibly because the effect of intra-household division of resources is not fully captured by the two indicators which are here assumed to affect food demand additively. To check whether the significance of the indicators is due to the failure of weak separability, we add to each equation the corresponding Box-Cox transform of medical expenditure and treat it as endogenous. As the Wald statistic for its joint significance in the system attests, weak separability cannot be rejected. The two indicators of parent's share of resources remain highly significant even when medical expenditure is included.

\section{Concluding Remarks}


A hallmark of altruism is the neutrality property that consumption is invariant of division to resources within the family. When applied to two-generation households, it implies that the demand system should not be affected by intergenerational division of resources. We were able to reject this neutrality implication since expenditure on precisely the food items favored by old generation is found to be sensitive to the older generation's share of household income.

The rejection of neutrality, however, does not necessarily mean a complete lack of altruism between parents and children. What it does mean is that there is a conflict between parents and children as to what the family's objective ought to be. There seems no question that children is altruistic toward parents albeit imperfectly; otherwise we would not see children co-residing with parents with very low income, as observed in our data. One could argue that co-residence is a manifestation of income risk-sharing. However, parent may have been poor before child is born. Even if parent and child can agree to a contract before observing income, it is difficult to explain why child provides help when parent is poor, despite the absence of enforcement. ${ }^{23}$

Evidence against neutrality presented in this paper for Japan and in Altonji et. al. (1992) for the U.S. casts serious doubts on the empirical basis for the view that generations act as if they form a single immortal dynasty.

23. A caveat: it is possible that children living with apparently very poor parents are doing so because the parent was able to offer a house to live. 


\section{Appendix: Possible Mis-coding of Missing Cases}

For two-generation households, there is clear evidence that genuine missing values are sometimes mis-coded as zeros. It is known that about $90 \%$ of two-generation households (with non-adult children) in which at least one individual 60 years or older is present received public pension in 1984. ${ }^{24}$ Table 6 reports the old generation's pension income for old nuclear households (Panel A), heads in two-generation households (Panel B), and non-heads in twogeneration households (Panel C). Thus the income of the old in Panel C is that of "all other household members". The fraction receiving positive pension income is somewhat lower in Panel B than in Panel A most likely because the old in Panel B are active people, still maintaining the household head status despite the presence of adult children co-residing in the same household. On the other hand, the old in Panel $\mathrm{C}$ are no longer head and are likely to be retired. That the fraction of them receiving positive pension income is much less can only be explained by a confusion of missing cases with zeros. Perhaps in many instances the respondent (usually the spouse of the head), unaware of the existence of the parents' pension income, left the relevant box in the questionnaire blank, which was officially coded as a zero. Many of these official zeros are undoubtedly genuine zeros, and true pension income for the rest of the official zeros is likely to be low. Furthermore, as reported in the table, the mean pension income for those reporting a positive value is lower for the old in two-generation households, particularly for non-heads. Therefore, it is highly likely that the true mean of pension income is substantially lower for the old in two-generation households than for old nuclear households.

24. Ministry of Health and Welfare, ibid., p. 102. 


\section{References}

Altonji, J., F. Hayashi, and L. Kotlikoff (1992) "Is the Extended Family Altruistically Linked? Direct Tests using Micro Data", American Economic Review.

$\longrightarrow$ - _ and _ - (1993) "The Effects of Income and Wealth on Time and Money Transfers between Parents and Children", mimeo., Northwestern University.

Ando and Kennickell (1987) "How Much (or Little) Life Cycle is There in Micro Data?" in Macroeconomics and Finance, Essays in Honor of Franco Modigliani (R, Dornbusch, S. Fischer, and J. Bossons, Eds.), MIT Press, Cambridge, Mass.

Becker (1981) A Treatise on the Family, Harvard University Press, Cambridge, Mass.

Behrman, J. (1992) "Intrahousehold Distribution and the Family", mimeo., University of Pennsylvania.

Bergstrom, T, L. Blume, and H. Varian (1986) "On the Private Provision of Public Goods", Journal of Public Economics 29, pp. 25-49.

Blundell, R., M. Browning, and C. Meghir (1989) "A Microeconomic Model of Intertemporal Substitution and Consumer Demand", mimeo., University College London.

Browning, M. and C. Meghir (1991) "The Effects of Male and Female Labor Supply on Commodity Demands", Econometrica 59, pp. 925-952.

Cai, J. (1989) "Are Husbands and Wives Altruistically Linked? Evidence from the Micro Data", mimeo., Boston University.

Christensen, L., D. Jorgenson, and L. Lau (1975) "Transcendental Logarithmic Utility Functions", American Economic Review 65, pp. 367-383.

Cox, D. and T. Jappelli (1990) "Credit Rationing and Private Transfers: Evidence from Survey Data", Review of Economics and Statistics 72, pp. 445-454.

Deaton, A. and J. Muelbauer (1980) Economics and Consumer Behavior, Cambridge University Press.

Hayashi, F. (1985) "Permanent Income Hypothesis and Consumption Durability: Analysis based on Japanese Panel Data", Quarterly Journal of Economics 90, pp. 895-916.

- A. Ando and R. Ferris (1988) "Life Cycle and Bequest Saving: A Study of Japanese and U.S. Households Based on the 1984 NSFIE Data and Data from the Survey of Consumer Finances", Journal of the Japanese and International Economies 2, pp. 450-491.

$\longrightarrow,-$, and — (1989) "Life Cycle and Bequest Savings", NIRA Research Output 2, pp. 38- 
86.

Ioannides, Y. and K. Kan (1993) "The Nature of Two-Directional Intergenerational Transfers of Money and Time: An Empirical Analysis", mimeo., VPI.

Kotlikoff, L. and J. Morris (1990) "Why Don't the Elderly Live with Their Children? A New Look", in Issues in the Economics of Aging (D. Wise Ed.), University of Chicago Press.

Ohtake, F. (1992) "Bequest Motives of Aged Households in Japan", mimeo., Osaka University.

Lundberg, S. and R. Pollak (1993a) "Separate Spheres Bargaining and the Marriage Market", mimeo., University of Washington, forthcoming in Journal of Political Economy.

— and — (1993b) "Distribution within Marriage: Noncooperative Bargaining Models", mimeo., University of Washington.

Rosenzweig, M. and K. Wolpin (1993) "Intergenerational Support and the Life-Cycle Incomes of Young Men and Their Parents: Human Capital Investments, Co-residence and Intergenerational Financial Transfers", Journal of Labor Economics 11, pp. 84-112.

— and — (1992) "Inequality among Young Adult Siblings, Public Assistance Programs, and Intergenerational Living Arrangements", mimeo., University of Pennsylvania.

Soldo, B. and P. Lauriat (1976) "Living Arrangements among the Elderly in the Unites States", Journal of Comparative Family Studies 7, pp. 351-366.

Schultz, T. (1990) "Testing Neoclassical Model of Family Labor Supply and Fertility", Journal of Human Resources 15, pp. 599-634.

Thomas, D. (1990) "Intra-Household Resource Allocation: An Inferential Approach", Journal of Human Resources 15, pp. 635-664.

Warr, P. (1983) "The Private Provision of a Public Good is Independent of the Distribution of Income", Economics Letters 13, pp. 207-211. 


\section{TABLE 1}

\section{Simple STATistics By HOUSEHOLd TyPe}

\begin{tabular}{|c|c|c|c|c|}
\hline & \multicolumn{4}{|c|}{ household type } \\
\hline & \multirow{2}{*}{$\begin{array}{l}\text { young } \\
\text { nuclear }\end{array}$} & \multirow{2}{*}{$\begin{array}{r}\text { old } \\
\text { nuclear }\end{array}$} & \multicolumn{2}{|c|}{ two-generation } \\
\hline & & & $\begin{array}{l}\text { younger } \\
\text { generation }\end{array}$ & $\begin{array}{r}\text { older } \\
\text { generation }\end{array}$ \\
\hline 1. sample size & 26,498 & 5,538 & \multicolumn{2}{|r|}{10,068} \\
\hline 2. population estimate (millions) & 20.5 & 5.0 & \multicolumn{2}{|r|}{6.2} \\
\hline 3. age of the generation & 36.3 & 64.3 & 37.0 & 67.1 \\
\hline 4. \#adults & 1.7 & 1.6 & 1.8 & 1.5 \\
\hline 5. \#non-adults & 1.3 & 0 & 1.5 & 0 \\
\hline 6. \%couples & 73.6 & 55.5 & 76.8 & 51.3 \\
\hline 7. \%single male & 15.9 & 8.1 & 12.9 & 6.8 \\
\hline 8. \%single female & 10.5 & 36.3 & 10.4 & 42.0 \\
\hline 9. annual income & 443.6 & 299.0 & 403.4 & 190.6 \\
\hline 10. \%annual income $=0$ & $0.3 \%$ & $0.8 \%$ & $10.6 \%$ & $29.2 \%$ \\
\hline 11. annual transfer receipts if $>0$ & 83.7 & 39.8 & 158.1 & 63.5 \\
\hline 12. \%annual transfer receipts $>0$ & $5.2 \%$ & $12.2 \%$ & $1.7 \%$ & $2.5 \%$ \\
\hline 13. total consumption expenditure & 277.2 & 194.7 & \multicolumn{2}{|c|}{334.3} \\
\hline 14. food & 79.5 & 46.5 & \multicolumn{2}{|r|}{91.8} \\
\hline 15. \%share, cereal & $10.6 \%$ & $13.9 \%$ & \multicolumn{2}{|r|}{$12.5 \%$} \\
\hline 16. \%share, seafood & $11.3 \%$ & $18.7 \%$ & \multicolumn{2}{|r|}{$17.3 \%$} \\
\hline 17. \%share, meat and dairies & $14.5 \%$ & $12.3 \%$ & \multicolumn{2}{|r|}{$17.5 \%$} \\
\hline 18. \%share, vegetables & $15.8 \%$ & $24.4 \%$ & \multicolumn{2}{|r|}{$19.0 \%$} \\
\hline 19. \%share, eating out & $34.2 \%$ & $16.9 \%$ & \multicolumn{2}{|r|}{$17.9 \%$} \\
\hline 20. \%share, other & $13.5 \%$ & $13.8 \%$ & \multicolumn{2}{|r|}{$15.7 \%$} \\
\hline
\end{tabular}

Note to Table 1: Weighted means are calculated as follows. Let $\mathrm{w}_{i}$ be the sampling weight from the survey. Because our sample excludes missing cases, the weight must be inflated so that the sample mean is unbiased for the population mean. The inflation factor is given by $\mathrm{x} /(\mathrm{y} \times \mathrm{z})$ where $\mathrm{x}=$ the number of families in the population, $y=$ sample size after elimination of missing cases, and $z=$ sample average of $\mathrm{w}_{\mathrm{i}}$. For singles, $\mathrm{x}=7.243$ million, $\mathrm{y}=3,924$. For non-singles, $\mathrm{x}=30.095$ million, $\mathrm{y}=$ 47,393. So, for example, the sum of the inflated $w_{i}$ over the sample is the estimate of the number of families in the population.

Annual income, annual transfer receipts, and expenditures in ten thousand yen. Transfer receipts are private monetary transfers from relatives and others. Income does not include transfers. Both income and transfers are for the 12 month period ending November 1984, while total consumption expenditure and food expenditure are over the 3 month period (September-November) at annual rates. A generation's income is the sum of husband's and wife's income if the generation is a couple. If the generation is an individual, its income is the individual's income. The definition of food components is as follows: cereal = rice, bread, noodles, flour and other serials, sea food $=$ fish and shellfish, meat and dairies = meat, dairy products and eggs, vegetables = vegetables and fruits, eatout = cooked food, restaurants, other $=$ oil, sweets, beverages, excludes tobacco and alcohl. 


\section{TABLE 2}

Probit Estimates: Determinants of Co-Residence

\begin{tabular}{|c|c|c|c|c|c|c|}
\hline \multirow{2}{*}{$\frac{\text { independent variable }}{\text { no. of observations }}$} & \multicolumn{2}{|c|}{$\begin{array}{l}\text { Column } 1 \\
\text { young }\end{array}$} & \multicolumn{2}{|c|}{ Column 2} & \multicolumn{2}{|c|}{ Column 3} \\
\hline & \multicolumn{2}{|c|}{36,566} & \multicolumn{4}{|c|}{15,606} \\
\hline$\%$ co-residence & \multicolumn{2}{|c|}{$27.5 \%$} & \multicolumn{4}{|c|}{$64.5 \%$} \\
\hline number of children & 0.089 & $(11)$ & & & - & \\
\hline single male & 0.23 & $(6.8)$ & -0.07 & $(1.1)$ & -0.09 & (1.4) \\
\hline single female & 0.099 & $(3.0)$ & 0.08 & $(2.1)$ & 0.02 & $(0.6)$ \\
\hline husband works & 0.11 & $(1.4)$ & -0.030 & $(0.9)$ & & \\
\hline wife works & 0.44 & $(27)$ & 0.011 & $(0.4)$ & 0.016 & $(0.6)$ \\
\hline age of the generation & $-5.0 \times 10^{-4}$ & $(0.5)$ & 0.034 & $(17)$ & 0.033 & (17) \\
\hline labor income & $-1.4 \times 10^{-4}$ & $(4.2)$ & $-2.7 \times 10^{-4}$ & $(5.5)$ & $-2.0 \times 10^{-4}$ & $(4.0)$ \\
\hline labor income $=0$ & 1.6 & $(35)$ & 0.55 & $(14)$ & 0.55 & $(14)$ \\
\hline pension income & & & $-2.8 \times 10^{-3}$ & (17) & $-2.4 \times 10^{-3}$ & (14) \\
\hline pension income $=0$ & & & 0.44 & (13) & 0.43 & (13) \\
\hline capital income & & & & & $-2.9 \times 10^{-4}$ & $(2.0)$ \\
\hline capital income $=0$ & $\longrightarrow$ & & $\longrightarrow$ & & 0.34 & $(12)$ \\
\hline mean log likelihood & -0.527 & & -0.52 & & -0.52 & \\
\hline
\end{tabular}

Note to Table 2: Income in ten thousand yen. Absolute values of $t$-values in parentheses. Capital income is the sum of dividends, interests, and rents. Since old nuclear households have no non-adult children, the equation for the old does not include the number of children on the right-hand-side. Other independent variables included are eight regional and four city-size dummies. 


\section{TABLE 3 \\ TOBIT Estimates: DeterminantS OF MONETARY TRANSFER RECEIPTS}

\begin{tabular}{|c|c|c|c|}
\hline independent variable & young & \multicolumn{2}{|c|}{ old } \\
\hline no. of observations & 26,498 & \multicolumn{2}{|c|}{5,538} \\
\hline$\%$ transfer $>0$ & $4.7 \%$ & \multicolumn{2}{|c|}{$9.2 \%$} \\
\hline mean transfer if $>0$ & 100.4 & \multicolumn{2}{|c|}{41.5} \\
\hline constant & $-255 \quad(11.4)$ & -148 & $(6.6)$ \\
\hline number of children & $30 \quad(6.7)$ & - & - \\
\hline head is single male & $(3.5)$ & 5.5 & $(0.5)$ \\
\hline head is single female & $(0.9)$ & 7.8 & (1.4) \\
\hline age of generation & 0.23 & 1.5 & (4.4) \\
\hline labor income & $-0.68 \quad(45.8)$ & -0.23 & $(15.2)$ \\
\hline pension income & $\longrightarrow$ & -0.31 & $(12.5)$ \\
\hline error variance & 274 & & \\
\hline mean log likelihood & -0.2259 & -0.2 & 42 \\
\hline
\end{tabular}

Note to Table 3: Annual income, annual monetary transfer receipts, and net financial assets in ten thousand yen. Absolute values of $t$-values in parentheses. The standard errors are calculated from the cross product of the score. The percent of the sample receiving monetary transfers and the mean transfer are different from those reported in Table 1 because here observations are not weighted. Regional and city-size dummies are not included in the equation because they turned out insignificant when included. 
TABLE 4

SHARE EQUATIONS: NUCLEAR HOUSEHOLdS (32,036 HOUSEHOLDS) PANEL A: TWO-STAGE LEAST SQUARES ESTIMATES FOR $\gamma=0$

\begin{tabular}{|c|c|c|c|c|c|c|c|c|c|c|}
\hline \multirow{2}{*}{$\frac{\text { Right-hand-side Variables }}{\# \text { children, } 0 \leq \text { age }<5}$} & \multicolumn{2}{|c|}{ Cereal } & \multicolumn{2}{|c|}{ Fish } & \multicolumn{2}{|c|}{ Meat \& Dairies } & \multicolumn{2}{|c|}{ Vegetables } & \multicolumn{2}{|c|}{ Eating Out } \\
\hline & 1.6 & (19) & 0.1 & (1) & 2.4 & $(33)$ & 0.1 & (1) & -6.5 & $(43)$ \\
\hline \#children, $5 \leq$ age $<10$ & 2.5 & (30) & -0.2 & (3) & 0.5 & $(7)$ & -0.1 & (2) & -4.4 & (29) \\
\hline \#children, $10 \leq$ age $<15$ & 3.6 & (38) & -0.3 & (3) & 1.1 & $(13)$ & -0.4 & (5) & -5.3 & (31) \\
\hline Hchildren, $15 \leq$ age $<20$ & 4.2 & (36) & -0.1 & (1) & 2.1 & (21) & -0.6 & (6) & -6.9 & (33) \\
\hline \#children, $20 \leq$ age $<25$ & 3.1 & (14) & -0.5 & (3) & 1.6 & $(8)$ & -0.6 & (3) & -4.5 & (11) \\
\hline marital status: head is single male & -8.0 & $(42)$ & -8.8 & $(51)$ & -12.8 & $(77)$ & -13.1 & (77) & 52.6 & (151) \\
\hline marital status: head is single female & -7.5 & (28) & -2.0 & $(8)$ & -4.0 & (17) & 0.0 & $(0)$ & 18.2 & $(37)$ \\
\hline emp. status: husband works & -1.4 & (7) & 2.2 & (13) & 1.0 & (6) & 0.3 & $(2)$ & -1.4 & (4) \\
\hline emp. status: husband works part-time & 1.3 & $(2)$ & -1.5 & $(2)$ & -1.0 & (1) & -0.3 & (0) & 0.6 & $(0)$ \\
\hline emp. status: wife works & -0.9 & (10) & 0.4 & $(5)$ & -1.0 & (12) & -1.2 & $(15)$ & 3.0 & (18) \\
\hline emp. status: wife works part-time & -1.1 & $(8)$ & -0.4 & $(3)$ & 0.2 & $(2)$ & 0.5 & $(4)$ & -1.0 & (4) \\
\hline age & 0.12 & $(28)$ & 0.25 & $(65)$ & -0.00 & (0) & 0.23 & $(63)$ & -0.56 & (73) \\
\hline$x^{\{\gamma\}}=\log ($ food $)$ & -9.0 & (29) & -1.9 & (7) & 0.5 & (2) & -0.8 & (3) & 16.9 & (30) \\
\hline mean of dependent variable (\%) & \multicolumn{2}{|c|}{12.2} & \multicolumn{2}{|c|}{13.8} & \multicolumn{2}{|c|}{16.0} & \multicolumn{2}{|c|}{18.3} & \multicolumn{2}{|c|}{24.9} \\
\hline standard deviation (\%) & \multicolumn{2}{|c|}{7.3} & \multicolumn{2}{|c|}{7.4} & \multicolumn{2}{|c|}{7.5} & \multicolumn{2}{|c|}{7.7} & \multicolumn{2}{|c|}{20.5} \\
\hline residual standard deviation (\%) & \multicolumn{2}{|c|}{6.8} & \multicolumn{2}{|c|}{6.1} & \multicolumn{2}{|c|}{5.9} & \multicolumn{2}{|c|}{6.0} & \multicolumn{2}{|c|}{12.3} \\
\hline
\end{tabular}

PANEL B: DIAGNOSTICS

\begin{tabular}{|c|c|c|c|c|c|}
\hline Sargan's test of over-identifying restrictions & $\begin{array}{l}\gamma=+1: \\
\gamma=0: \\
\gamma=-1:\end{array}$ & $\begin{array}{l}\chi^{2}(20) \\
\chi^{2}(20) \\
\chi^{2}(20)\end{array}$ & $\begin{array}{l}=136.6 \\
=126.7 \\
=129.0\end{array}$ & $\begin{array}{l}\left(\mathrm{p} \text {-value }=3.2 \times 10^{-19}\right) \\
\left(\mathrm{p} \text {-value }=1.6 \times 10^{-17}\right) \\
\left(\mathrm{p} \text {-value }=6.0 \times 10^{-18}\right)\end{array}$ & $\begin{array}{l}\text { [equivalent } t \text {-value }=9.0] \\
\text { [equivalent } t \text {-value }=8.5] \\
\text { [equivalent } t \text {-value }=8.6]\end{array}$ \\
\hline $\begin{array}{l}\text { Wald test of absence of medical expenditure } \\
\text { in the share equations }\end{array}$ & $\begin{array}{l}\gamma=+1: \\
\gamma=0: \\
\gamma=-1:\end{array}$ & $\begin{array}{l}\chi^{2}(5)= \\
\chi^{2}(5)= \\
\chi^{2}(5)=\end{array}$ & $\begin{array}{l}48.2 \\
34.7 \\
13.0\end{array}$ & $\begin{array}{l}\left(\mathrm{p} \text {-value }=3.3 \times 10^{-9}\right) \\
\left(\mathrm{p} \text {-value }=1.7 \times 10^{-6}\right) \\
\left(\mathrm{p} \text {-value }=2.4 \times 10^{-2}\right)\end{array}$ & $\begin{array}{l}\text { [equivalent } t-v \text { alue }=5.9] \\
\text { [equivalent } t-v a l u e=4.8] \\
\text { [equivalent } t-v a l u e=2.3\end{array}$ \\
\hline
\end{tabular}

Note to Table 4: Food is treated as endogenous, instrumented by household income, its square, capital income, its square, and net financial assets. Other right hand variables included are: eight regional and four city-size dummies. 


\section{TABLE 6}

\section{PENSION INCOME BY TyPE}

Panel A: Old Nuclear

\begin{tabular}{|c|r|r|r|r||}
\hline \multirow{2}{*}{} & \multicolumn{3}{|c|}{ age } & \multirow{2}{*}{ total } \\
\cline { 2 - 5 } & $55-<65$ & $65-<75$ & \multicolumn{1}{|c|}{$75-$} & 5,538 \\
\hline cell size & 3,416 & 1,787 & 335 & $75.5 \%$ \\
\hline \%pension income $>0$ & $63.6 \%$ & $94.2 \%$ & $96.7 \%$ & 160.0 \\
\hline mean pension income if > $>$ & 167.5 & 158.1 & 121.2 & \\
\hline
\end{tabular}

Panel B: Heads in Two-Generation Households

\begin{tabular}{||c|r|r|r|r||}
\hline & \multicolumn{3}{|c|}{ age } & \multirow{2}{*}{} \\
\cline { 2 - 5 } & $55-<65$ & $65-<75$ & \multicolumn{1}{c|}{$75-$} & total \\
\hline cell size & 2,460 & 835 & 91 & 3,386 \\
\hline \%pension income > & $48.7 \%$ & $78.3 \%$ & $82.4 \%$ & $56.9 \%$ \\
\hline mean pension income if $>0$ & 142.8 & 123.7 & 111.3 & 94.3 \\
\hline
\end{tabular}

Panel C: Non-Heads in Two-Generation Households

\begin{tabular}{|c|r|r|r|r||}
\hline & \multicolumn{3}{|c|}{ age } & \multirow{2}{*}{ total } \\
\cline { 2 - 5 } & $55-<65$ & $65-<75$ & \multicolumn{1}{|c|}{$75-$} & 6,682 \\
\hline cell size & 1,831 & 3,146 & 1,705 & $48.0 \%$ \\
\hline \%pension income > & $43.1 \%$ & $51.8 \%$ & $46.1 \%$ & 85.6 \\
\hline mean pension income if $>0$ & 103.4 & 84.1 & 70.6 & \\
\hline
\end{tabular}

Note to Table 6: Pension income in ten thousand yen. 
FIGURE 1

DERIVATION OF SAMPLES

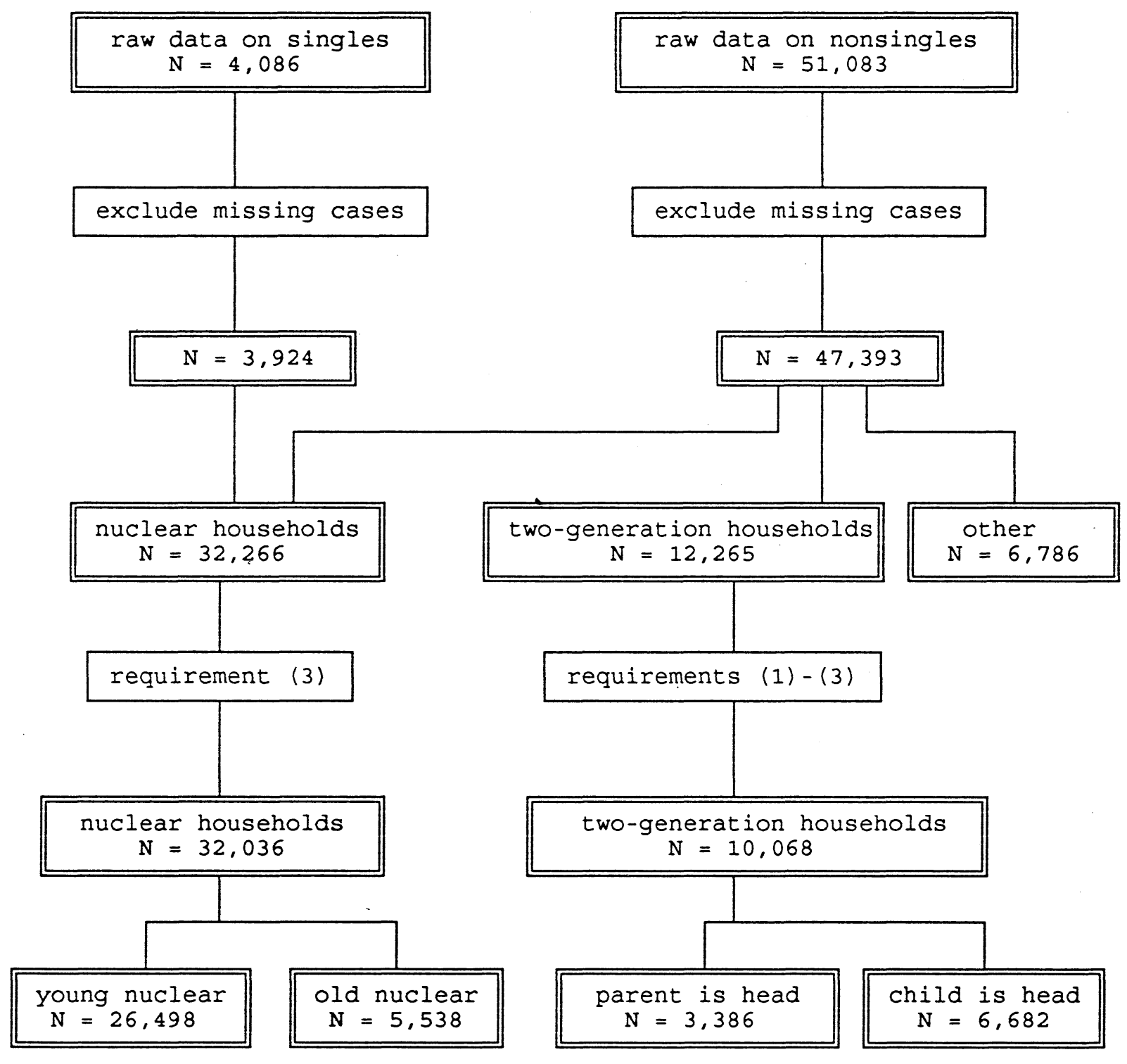


Figure 2

Parents's and Children's Income in Extended Families, 1984

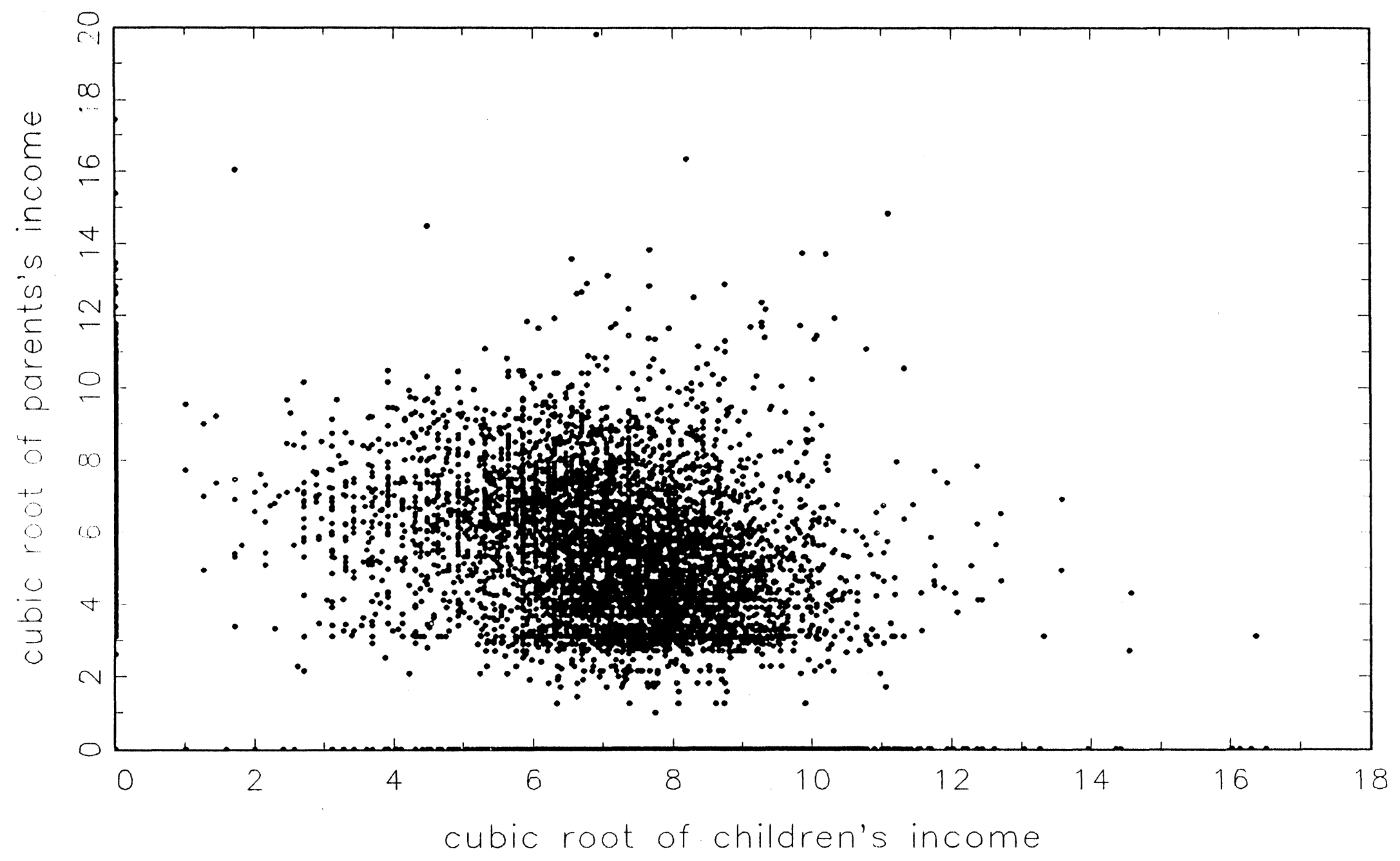

